\title{
ANALISIS MIKROBIOLOGI BEBERAPA SUSU KEDELAI TANPA MEREK YANG BEREDAR DI KABUPATEN MAROS SULAWESI SELATAN
}

\author{
Santri ${ }^{*}$, Siska Nuryanti ${ }^{*}$, Tadjuddin Naid ${ }^{\star *}$ \\ *) Fakultas Farmasi Universitas Muslim Indonesia Makassar \\ ${ }^{* *}$ Fakultas Farmasi Universitas Hasanuddin Makassar \\ Email : tadjuddinnaid@yahoo.co.id.
}

\begin{abstract}
Research about the micribiological analyze has been of some soys milk without brand marketed in Maros, South Sulawesi. The research to be compared with the requirements that have been determined by the director-general of the $P O M$. The research conducted by determining the number plate total (ALT) bacteria, Total Plate Number (ALT) moulds as well as the presence of microbial pathogens in some soys milk without brand. The research methods using Standard Plate Count (SPC) to calculate the total amount of bacteria and mold, as wel as the identification method to determine the number of pathogenic bacteria. The results of this study indicating that the sample of $C, E$ and $H$ microbial has fulfilled the requirements of soy milk pathogenic bacteria test of Coliform (-), Salmonella sp (-), Staphylococcus aureus (-) and Bacillus cereus (-). Sample $C, E$ and $H$ has fulfilled the requiremqnts of $A L T$ bacteria and sample $C$ has fulfilled the requiremqnts of ALT moulds. But the $E$ dan $H$ sample have has not fulfilled the requirements.
\end{abstract}

Key words: Soy milk, microbiologcal analyze, indonesian national standard.

\section{PENDAHULUAN}

Di Indonesia beberapa komoditi kacang-kacangan telah digunakan sebagai bahan dasar untuk membuat susu yang dikenal sebagai susu nabati. Susu nabati yang umum ditemukan dipasaran adalah susu kedelai, baik dalam kemasan bermerek maupun yang tidak bermerek. Dimana kemasan yang tidak bermerek tersebut tidak mencantumkan surat izin produksinya sehingga sebagian masyarakat masih meragukan keamanannya untuk dikonsumsi. (1) Dalam pengujian cemaran mikrobiologik ada tiga kelompok mikroorganisme yamg perlu diperhatikan yaitu total mikroorganisme, mikroorganisme indikator dan pembusuk. (2)

Kontaminasi makanan atau minuman adalah terdapatnya bahan atau mikroorganisme dalam makanan atau minuman secara tidak sengaja. Bahan atau organisme yang berbahaya tersebut disebut kontaminan keberadaan kontaminan dalam makanan atau minuman 
Analisis mikrobiologi beberapa susu kedelai tanpa merek yang beredar di kabupaten maros Sulawesi Selatan

kadang-kadang hanya mengakibatkan penurunan nilai estetis dari makanan atau minuman tersebut. Meskipun demikian kontaminan dapat pula menimbulkan efek yang lebih merugikan antara lain sakit dan permukaan akut, sakit kronis bahkan kematian bagi orang yang mengkonsumsi makanan yang terkontaminasi. (3)

Menurut Standard Nasional Indonesia (SNI) No.06.8-7388-2009 persyaratan cemaran mikroba pada produk sari kedelai yaitu mengandung angka lempeng total bakteri maksimal $5 \times 10^{4} \mathrm{koloni} / \mathrm{mL}$, nilai MPN bakteri coliform $<3 / \mathrm{mL}$ Salmonella $s p$ harus negatif/25 mL, Staphylococcus aureus $1 \times 10^{2}$ koloni $/ \mathrm{mL}$, Bacillus cereus $1 \times 10^{3}$ koloni/mL dan kapang $5 \times 10^{1}$ koloni/mL.

Hal inilah yang mendasari perlunya dilakukan penelitian analisis mikrobiologis susu kedelai tanpa merek yang beredar di Kabupaten Maros, Sulawesi Selatan.

\section{METODE KERJA}

Jenis penelitian yang dilakukan adalah secara eksperimental yang merupakan penelitian di laboratorium dengan menggunakan eksperimen sederhana.

\section{Alat dan Bahan}

Alat-alat yang digunakan pada penelitian ini yaitu autoklaf (Smic Model $\left.Y X-280 B^{\circledR}\right)$, botol pengencer, cawan petri $\left(\mathrm{CMSI}^{\circledR}\right)$, gelas Erlenmeyer (Iwaki, Pyrex ${ }^{\circledR}$ ), gelas piala (Iwake, Pyrex ${ }^{\circledR}$ ), incubator aerob (Memmert $^{\circledR}$ ), lampu spiritus, Laminar Air Flow (LAF) (R-65), oven $\left(\right.$ Memmert $\left.^{\circledR}\right)$, ose bulat, spoit, sendok tanduk, tabung reaksi, tabung durham dan timbangan analitik.

Bahan-bahan yang digunakan pada penelitian ini yaitu aquadest, etanol 70\%, medium Eosin Metilen Blue Agar (EMBA), medium Laktosa Broth (LB), medium Mannitol Egg-Yolk Polymixin Agar (MYPA), medium Nutrient Agar (NA), medium Potato Dextrosa Agar (PDA), medium Pepton Water (PW), medium Selenite Cystein Broth (SCB), medium Vogel Johnson Agar (VJA), medium Salmonella Shigella Agar (SSA) dan sampel susu kedelai tanpa merek.

\section{Prosedur Kerja}

\section{Sterilisasi alat}

Alat-alat yang digunakan dicuci lalu dibilas dengan air suling. Kemudian disterilkan dengan menggunakan oven pada suhu $180^{\circ} \mathrm{C}$ selama 2 jam untuk alat gelas. Alatalat logam disterilkan dengan cara dipijarkan dengan menggunakan 
Analisis mikrobiologi beberapa susu kedelai tanpa merek yang beredar di kabupaten maros Sulawesi Selatan

lampu spirtus selama 30 detik. Alatalat karet, plastik (tidak tahan pemanasan dengan suhu tinggi) disterilkan dengan autoklaf pada suhu $121^{\circ} \mathrm{C}$ selama 15 menit. ${ }^{4}$

\section{Perlakuan}

\section{Pengambilan sampel}

Beberapa sampel susu kedelai tanpa merek yang beredar di Kabupaten Maros.

\section{Pengenceran sampel}

Sampel susu kedelai tanpa merek dibuat pengenceran $10^{\circ}$ sampai $10^{-4}$ atau sesuai derajat kombinasi bahan. Dengan cara aseptik sampel susu kedelai tanpa merek diambil sebanyak $1 \mathrm{~mL}$ dan dimasukkan kedalam botol pengencer steril, kemudian ditambahkan $9 \mathrm{~mL}$ air suling steril dan di homogen maka diperoleh pengenceran $10^{\circ}$. Untuk pengenceran selanjutnya, dipipet $1 \mathrm{~mL}$ dari $10^{\circ}$ dimasukkan kedalam botol pengencer yang berisi $9 \mathrm{~mL}$ air suling steril, dihomogenkan dan diperoleh pengenceran $10^{-1}$. Demikian selanjutnya dilakukan cara yang sama untuk pengenceran $10^{-2}, 10^{-3}$ dan $10^{-4}$.

\section{Pengujian Mikrobiologis}

Penentuan angka lempeng total bakteri secara Standar Plate Count (SPC)

Dari masing-masing pengenceran $10^{-2}, 10^{-3}$ dan $10^{-4}$ dipipet
$1 \mathrm{~mL}$ kedalam cawan petri dan ditambahkan medium Nutrient Agar (NA) sebanyak $9 \mathrm{~mL}$ kemudian dihomogenkan. Diinkubasi pada suhu $37^{\circ} \mathrm{C}$ selama 24 jam. Diamati dan dihitung jumlah koloni yang tumbuh.

Penentuan angka lempeng total kapang secara Standar Plate Count (SPC)

Dari masing-masing pengenceran $10^{0}, 10^{-1}$, dan $10^{-2}$ dipipet $1 \mathrm{~mL}$ kedalam cawan petri dan ditambahkan medium Potato Dextrosa Agar (PDA) sebanyak $9 \mathrm{~mL}$ kemudian dihomogenkan. Diinkubasi pada suhu $37^{\circ} \mathrm{C}$ selama $3 \times 24$ jam. Jumlah koloni yang tumbuh, merupakan kapang untuk setiap $1 \mathrm{~mL}$ sampel.

Penentuan jumlah total bakteri Coliform secara Most Probable Number (MPN)

\section{Tes Perkiraan}

Merupakan tes pendahuluan ada tidaknya bakteri golongan Coliform. Disiapkan 12 tabung reaksi masing-masing terdiri dari 3 tabung yang didalamnya terdapat tabung durham dalam keadaan terbalik. Dari pengenceran $10^{-1}$ dipipet $1 \mathrm{~mL}$ kedalam tabung reaksi seri pertama yang berisi medium Laktosa Broth (LB) $9 \mathrm{~mL}$. Dari pengenceran $10^{-2}$ dipipet $1 \mathrm{~mL}$ kedalam tabung reaksi seri kedua 
Analisis mikrobiologi beberapa susu kedelai tanpa merek yang beredar di kabupaten maros Sulawesi Selatan

yang berisi medium Laktosa Broth (LB) $9 \mathrm{~mL}$, dilakukan hal yang sama untuk pengenceran $10^{-3}$. Semua tabung dihomogenkan dan diinkubasi selama 24-48 jam pada suhu $37^{\circ} \mathrm{C}$. Reaksi positif ditandai dengan perubahan warna hijau menjadi kuning dan terbentuk gas dalam tabung durham.

2. Tes penentuan

Dari tabung yang memberikan hasil positif, diambil 1 ose kemudian diinokulasi secara goresan pada medium Eosin Metilen Blue Agar (EMBA). Selanjutnya diinkubasi pada suhu $37^{\circ} \mathrm{C}$ selama 24 jam. Reaksi positif ditandai dengan terbentuknya koloni berwarna hijau metalik.

\section{Identifikasi bakteri Salmonella sp.}

Sampel dipipet secara aseptis sebanyak $1 \mathrm{~mL}$ pada pengenceran $10^{-}$ 1 untuk diinokulasikan ke dalam medium Selenite Cystein Broth (SCB) $9 \mathrm{~mL}$, kemudian diinkubasi pada suhu $37^{\circ} \mathrm{C}$ selama 24 jam, reaksi positif ditandai dengan terbentuknya endapan coklat. Hasil yang diperoleh diinokulasikan dengan metode tuang pada medium Salmonella Shigella Agar (SSA) selanjutnya diinkubasi pada suhu $37^{\circ} \mathrm{C}$ selama 24 jam. Diamati koloni yang tumbuh, dinyatakan positif apabila tumbuh koloni hitam dengan zona kuning.

\section{Identifikasi bakteri Staphylococcus aureus}

Sampel dipipet secara aseptis sebanyak $1 \mathrm{~mL}$ pada masing-masing pengenceran $10^{0}, 10^{-1}, 10^{-2}$ untuk diinokulasikan ke dalam medium Pepton Water (PW) $9 \mathrm{~mL}$ kemudian diinkubasi pada $37^{\circ} \mathrm{C}$ selama 24 jam. Hasil positif terjadi kekeruhan disertai dengan terbentuknya endapan pada dasar tabung, kemudian dilanjutkan pada medium selektif yaitu medium Vogel Jhonson Agar diinokulasikan dengan metode tuang, selanjutnya diinkubasi pada suhu $37^{\circ} \mathrm{C}$ selama 24 jam. Diamati koloni yang tumbuh dinyatakan positif apabila tumbuh koloni hitam zona kuning.

\section{Identifikasi bakteri Bacillus cereus}

Sampel dipipet secara aseptis sebanyak $0,25 \mathrm{~mL}$ dari setiap pengenceran $\left(10^{-1}, 10^{-2}, 10^{-3}\right)$, kemudian diinokulasi diatas permukaan Mannitol Egg-Yolk Polymixin Agar (MYPA). Setelah itu, diinkubasi pada suhu $37^{\circ} \mathrm{C}$ selama 24 jam. Diamati koloni yang tumbuh dinyatakan positif apabila tumbuh koloni berwarna merah muda pada medium Mannitol Egg-Yolk Polymixin Agar (MYPA). 
Analisis mikrobiologi beberapa susu kedelai tanpa merek yang beredar di kabupaten maros Sulawesi Selatan

HASIL PENELITIAN

Pengambilan sampel

Sampel susu kedelai diambil dari beberapa penjual yang beredar di Kabupaten Maros.

\section{Pengujian Sampel}

Penentuan Angka Lempeng Total Bakteri (SPC)
Hasil analisis data angka lempeng total bakteri dengan metode Standard Plate Count menunjukan bahwa sampel $\mathrm{C}, \mathrm{E}$ dan $\mathrm{H}$ memenuhi persyaratan berdasarkan Standar Nasional Indonesia (SNI) No.06.87388-2009. Hasil dapat dilihat pada tabel berikut :

Tabel 1. Hasil perhitungan jumlah Total Bakteri ( SPC) per $1 \mathrm{ml}$ Susu kedelai Tanpa Merek

\begin{tabular}{cccc}
\hline Kode Sampel & $\begin{array}{c}\text { Hasil Perhitungan } \\
(\text { Koloni/mL) }\end{array}$ & $\begin{array}{c}\text { Persyaratan } \\
(\text { Koloni/mL) }\end{array}$ & Keterangan \\
\hline $\mathrm{C}$ & $7,5 \times 10^{3}$ & $5 \times 10^{4}$ & Memenuhi persyaratan \\
$\mathrm{E}$ & $8,5 \times 10^{3}$ & $5 \times 10^{4}$ & Memenuhi persyaratan \\
$\mathrm{H}$ & $3,7 \times 10^{3}$ & $5 \times 10^{4}$ & Memenuhi persyaratan \\
\hline
\end{tabular}

Penentuan Angka Lempeng Total Jamur (SPC)

Hasil analisis data angka lempeng total jamur dengan metode Standard Plate Count menunjukan bahwa sampel C memenuhi

Tabel 2. Hasil perhitungan jumlah Total Kapang (SPC) per $1 \mathrm{~mL}$ Susu Kedelai Tanpa Merek persyaratan tapi sampel $\mathrm{E}$ dan $\mathrm{H}$ tidak memenuhi persyaratan kapang berdasarkan Standar Nasional Indonesia (SNI) No.06.8-7388-2009. Hasil dapat dilihat pada tabel berikut :

\begin{tabular}{cccc}
\hline $\begin{array}{c}\text { Kode } \\
\text { Sampel }\end{array}$ & $\begin{array}{c}\text { Hasil Perhitungan } \\
(\text { Koloni } / \mathbf{m L})\end{array}$ & $\begin{array}{c}\text { Persyaratan } \\
(\text { Koloni/mL) }\end{array}$ & Keterangan \\
\hline $\mathrm{C}$ & $2,6 \times 10^{1}$ & $5 \times 10^{1}$ & $\begin{array}{c}\text { Memenuhi persyaratan } \\
\mathrm{E}\end{array}$ \\
$\mathrm{H}$ & $7,1 \times 10^{1}$ & $5 \times 10^{1}$ & Tidak memenuhi persyaratan \\
& $7,0 \times 10^{1}$ & $5 \times 10^{1}$ & Tidak memenuhi persyaratan \\
\hline
\end{tabular}

Penentuan jumlah koloni bakteri Koliform secara MPN

Hasil analisis data penentuan jumlah bakteri Coliform secara Most Probable Number pada sampel $\mathrm{C}, \mathrm{E}$ dan $\mathrm{H}$ 
Analisis mikrobiologi beberapa susu kedelai tanpa merek yang beredar di kabupaten maros Sulawesi Selatan

Tabel 3. Hasil Pengamatan Jumlah Total Bakteri Coliform (MPN) per $1 \mathrm{~mL}$ Susu Kedelai Tanpa Merek

\begin{tabular}{ccccc}
\hline Kode Sampel & \multicolumn{3}{c}{ Pengenceran } & Nilai Tabel \\
\hline C & $\mathbf{1 0}^{-1}$ & $\mathbf{1 0}^{-2}$ & $\mathbf{1 0}^{-3}$ & $<0,03$ \\
E & --- & -- & -- & $<0,03$ \\
H & -- & --- & -- & $<0,03$ \\
\hline
\end{tabular}

Tabel 4. Hasil Perhitungan Jumlah Total Bakteri Coliform (MPN) per $1 \mathrm{~mL}$ Susu Kedelai Tanpa Merek

\begin{tabular}{cccc}
\hline $\begin{array}{c}\text { Kode } \\
\text { Sampel }\end{array}$ & $\begin{array}{c}\text { Nilai MPN Sampel hasil } \\
\text { perhitungan } \\
(\text { APM/mL) }\end{array}$ & $\begin{array}{c}\text { Persyaratan } \\
(\text { APM } / \mathbf{m L})\end{array}$ & Keterangan \\
\hline $\mathrm{C}$ & $<0,3$ & $<3$ & Memenuhi Persyaratan \\
$\mathrm{E}$ & $<0,3$ & $<3$ & Memenuhi Persyaratan \\
$\mathrm{H}$ & $<0,3$ & $<3$ & Memenuhi Persyaratan \\
\hline
\end{tabular}

\section{Identifikasi bakteri pathogen}

Pada penelitian ini diidentifikasi mikroba patogen digunakan medium pengaya dan dilanjutkan kemedium selektif. Beberapa medium ini digunakan untuk identifikasi mikroba pathogen antara lain medium Salenite Cystein Broth (SCB) dilanjutkan ke medium selektif Salmonella Sgella
Agar (SSA) untuk identifikasi Salmonella sp, Pepton Water (PW) dilanjutkan ke medium selektif Vogel Jhonson Agar (VJA) untuk identifikasi Staphylococcus aureus dan medium Mannitol Egg-Yolk Polymixin Agar (MYPA) untuk mengidentifikasi bakteri Bacillus cereus. Hasil penelitian dapat dilihat pada tabel berikut:

Tabel 5: Hasil Pengamatan Bakteri Patogen Sampel Susu Kedelai Tanpa Merek

\begin{tabular}{|c|c|c|c|c|c|c|c|c|c|c|c|}
\hline \multirow{3}{*}{$\begin{array}{l}\text { Kode } \\
\text { Sampel }\end{array}$} & \multicolumn{2}{|c|}{$\begin{array}{c}\text { Staphylococcus } \\
\text { aureus }\end{array}$} & \multicolumn{6}{|c|}{ Salmonella sp } & \multicolumn{3}{|c|}{ Bacillus cereus } \\
\hline & SCB & SSA & & PW & & & VJA & & & MYPA & \\
\hline & $10^{-1}$ & $10^{-1}$ & $10^{0}$ & $10^{-1}$ & $10^{-2}$ & $10^{0}$ & $10^{-1}$ & $10^{-2}$ & $10^{-1}$ & $10^{-2}$ & $10^{-3}$ \\
\hline $\mathrm{C}$ & - & - & - & - & - & - & - & - & - & - & - \\
\hline$E$ & - & - & - & - & - & - & - & - & - & - & - \\
\hline $\mathrm{H}$ & - & - & - & - & - & - & - & - & - & - & - \\
\hline
\end{tabular}

\section{Keterangan :}

$+\quad=$ Terdapat Bakteri

- $\quad=$ Tidak Terdapat Bakteri

SCB = Salenite Cystein Broth

SSA = Salmonella Sgella Agar

LB = Laktosa Broth

$\mathrm{EMBA}=$ Eosin Metilen Blue Agar

$\mathrm{PW}=$ Pepton Water

VJA = Vogel Jonson Agar

MYPA = Mannitol Egg-Yolk Polymixin Agar 
Analisis mikrobiologi beberapa susu kedelai tanpa merek yang beredar di kabupaten maros Sulawesi Selatan

\section{PEMBAHASAN}

Bahaya biologi (mikroba) pada pangan perlu mendapat perhatian karena jenis bahaya ini yang sering menjadi agen penyebab kasus keracunan pangan. Escherichia coli merupakan bakteri patogen yang sering menyebabkan keracunan pangan dan juga menjadi salah satu mikroba indikator sanitasi. Sedangkan Staphylococcus aureus merupakan bakteri yang biasa menghuni hidung, mulut, tenggorokan, maupun kulit. Keberadaan Escherichia coli pada pangan dapat menunjukkan praktek sanitasi lingkungan yang buruk sedangkan adanya Staphylococcus aureus mengidentifikasi praktek higiene yang kurang.

Berdasarkan hasil ketetapan persyaratan Standar Nasional Indonesia (SNI) No.06.8-7388-2009 persyaratan cemaran mikroba pada produk sari kedelai yaitu mengandung angka lempeng total bakteri maksimal $5 \times 10^{4} \mathrm{koloni} / \mathrm{mL}$, nilai MPN bakteri coliform $<3 / \mathrm{mL}$ Salmonella $s p$ harus negatif/25 mL, Staphylococcus aureus $1 \times 10^{2}$ koloni/mL, Bacillus cereus $1 \times 10^{3}$ koloni/mL dan kapang $5 \times 10^{1}$ koloni/mL.

Pada penelitian ini dilakukan pengujian beberapa sampel susu kedelai tanpa merek. Hal ini dimaksudkan agar dapat dilihat tingkat keamanan sampel dari segi mikrobiologis, sehingga digunakan perbandingan sampel untuk melihat tingkat kontaminasi mikroorganisme.

Pengerjaan menggunakan pengenceran dengan variasi konsentrasi yaitu $10^{0}, 10^{-1}, 10^{-2}, 10^{-3}$ dan $10^{-4}$. Hal ini dilakukan untuk mendapatkan konsentrasi yang berbeda dan mengurangi tingkat kontaminasi sehingga memudahkan pengamatan bakteri atau koloni yang tumbuh serta untuk menginaktifkan pengawet yang ada dalam sampel.

Hasil yang diperoleh pada jumlah angka lempeng total bakteri pada sampel $\mathrm{C}$ adalah $7,5 \times 10^{3}$ koloni/mL, sampel $\mathrm{E}$ adalah 8,5 $\times 10^{3}$ koloni/mL dan sampel $\mathrm{H}$ adalah $3,7 \times$ $10^{3} \mathrm{koloni} / \mathrm{mL}$. Dari hasil penelitian ini jika dibandingkan Standar Nasional Indonesia (SNI) No.06.8-7388-2009 yaitu $5 \times 10^{4}$ koloni $/ \mathrm{mL}$, maka semua sampel telah memenuhi persyaratan Jumlah Nilai ALT.

Sedangkan untuk angka lempeng total kapang didapatkan hasil pada sampel $\mathrm{C}$ adalah $2,6 \times 10^{1}$ $\mathrm{kol} / \mathrm{mL}$, sampel $\mathrm{E}$ adalah $5,1 \times 10^{1}$ koloni/mL dan sampel $\mathrm{H}$ adalah 7,0 x $10^{1}$ koloni/mL. Dari hasil penelitian ini jika dibandingkan dengan Standar Nasional Indonesia (SNI) No.06.8- 
Analisis mikrobiologi beberapa susu kedelai tanpa merek yang beredar di kabupaten maros Sulawesi Selatan

7388-2009 bahwa susu kedelai tidak diperkenankan Angka Lempeng Total jamur lebih dari $5 \times 10^{1}$ koloni $/ \mathrm{mL}$ maka sampel $C$ telah memenuhi persyaratan, sedangkan sampel E dan $\mathrm{H}$ memiliki nilai diatas batas maksimum kapang yang telah ditetapkan. Hal tersebut dapat disebabkan oleh beberapa hal, diantaranya adalah proses pembuatan yang kurang aseptis, kemasan dan penyimpanan sampel yang kurang baik.

Jumlah Most Probable Number (MPN) Coliform untuk sampel C, E dan $\mathrm{H}$ adalah $<3 \mathrm{APM} / \mathrm{mL}$. Dari hasil penelitian ini jika dibandingkan dengan persyaratan Standar Nasional Indonesia (SNI) No.06.8-7388-2009 untuk MPN Coliform yaitu $<3 \mathrm{APM} / \mathrm{mL}$, maka sampel $\mathrm{C}$, E dan $\mathrm{H}$ memenuhi persyaratan secara mikrobiologis berdasarkan nilai MPN.

Untuk identifikasi bakteri patogen Staphylococcus aureus, hasil yang diperolah yaitu sampel C, E dan $\mathrm{H}$ tampak jernih dan tidak terdapat endapan pada dasar tabung. Kemudian, pada medium lanjutan hasilnya negatif karena tidak tumbuh koloni hitam dengan zona kuning. Sehingga sampel C, E dan $H$ memenuhi persyaratan berdasarkan ketetapan Standar Nasional Indonesia tentang bakteri Staphylococcus aureus yaitu $1 \times 10^{2}$ koloni $/ \mathrm{mL}$.

Dari pengujian sampel C, E dan $\mathrm{H}$ medium selektif Salmonella Shigella Agar (SSA) yang telah dilakukan diperoleh hasil yang negatif karena tidak tumbuh koloni hitam dengan zona kuning. Sehingga sampel C, E dan $\mathrm{H}$ memenuhi persyaratan berdasarkan ketetapan Standar Nasional Indonesia tentang bakteri Salmonella sp yaitu negatif/ $25 \mathrm{~mL}$.

Dari pengujian sampel C, E dan H medium selektif Salmonella Shigella Agar (SSA) yang telah dilakukan diperoleh hasil yang negatif karena tidak tumbuh koloni hitam dengan zona kuning. Sehingga sampel C, E dan $\mathrm{H}$ memenuhi persyaratan berdasarkan ketetapan Standar Nasional Indonesia tentang bakteri Salmonella $s p$ yaitu negatif/ $25 \mathrm{~mL}$.

Dari hasil analisis kuantitatif yang meliputi Standart Plate Count (SPC) pada ALT bakteri dan angka kapang, MPN Coliform, identifikasi bakteri patogen Staphylococcus aureus dan Bacillus cereus, serta analisis kualitatif yaitu identifikasi mikroba patogen Salmonella $s p$ menunjukkan bahwa semua sampel memenuhi persyaratan. Namun sampel $E$ dan $H$ pada pengujian Angka Lempeng Total (ALT) kapang 
Analisis mikrobiologi beberapa susu kedelai tanpa merek yang beredar di kabupaten maros Sulawesi Selatan

melebihi ketetapan Standar Nasional Indonesia (SNI) No.06.8-7388-2009 yaitu $5 \times 10^{1} \mathrm{koloni} / \mathrm{mL}$.

\section{KESIMPULAN}

Berdasarkan hasil penelitian yang dilakukan dapat disimpulkan bahwa sampel $\mathrm{C}$, $\mathrm{E}$ dan $\mathrm{H}$ memenuhi persyaratan Standar Nasional Indonesia (SNI) No.06.8-7388-2009 tentang produk susu kedelai yaitu bakteri patogen Coliform (-), Salmonella sp (-), Staphylococcus aureus (-), dan Bacillus cereus (-). Untuk nilai Angka Lempeng Total (ALT) Bakteri semua sampel memenuhi memenuhi persyaratan. Untuk nilai Angka Lempeng Total (ALT) kapang, sampel C memenuhi persyaratan sedangkan sampel $E$ dan $\mathrm{H}$ memiliki nilai yang melebihi batas maksimal Angka Lempeng Total (ALT) kapang menurut Standar Nasional Indonesia (SNI) No.06.8-7388-2009.

\section{DAFTAR PUSTAKA}

1. Salim, E., 2012. Aneka Olahan Kedelai. Lily Publisher, Yogyakarta.

2. Djide, M.N., Kadir, S., 2003. Mikrobiologi Farmasi Terapan. Universitas Hasanuddin, Makassar.

3. Purnawijayanti, A.H., 2001. Sanitasi higiene dan keselamatan kerja dalam pengolahan makanan, Kanisius, Yogyakarta.

4. Djiwosaputro, D., 1978. DasarDasar Mikrobiologi. Penerbit Djambatan, Jakarta.

5. Pelczar, M.J., 1988. Dasar-Dasar Mikrobiologi, Penerjemah R.S. Hadiatomo, dkk., UI Press, Jakarta.

6. Pratiwi, S., 2008. Mikrobiologi Farmasi. Penerbit Erlangga, Jakarta.

7. Waluyo, L., 2008. Teknik dan Dasar Dalam Mikrobiologi, Universitas Muhammadiyah, Malang. 